\title{
Convergence theorem for an iterative algorithm of $\lambda$-strict pseudocontraction
}

XinKuan Chai and Yisheng Song*

* Correspondence:

songyisheng123@yahoo.com.cn College of Mathematics and Information Science, Henan Normal University, XinXiang 453007, PR China

\section{Abstract}

In this article, we prove strong convergence of sequence generated by the following iteration sequence for a class of Lipschitzian pseudocontractive mapping $T$ :

$$
x_{n+1}=\beta_{n} u+\left(1-\beta_{n}\right)\left[\alpha_{n} T x_{n}+\left(1-\alpha_{n}\right) x_{n}\right]
$$

whenever $\left\{\alpha_{n}\right\}$ and $\left\{\beta_{n}\right\}$ satisfy the appropriate conditions.

2000 AMS Subject Classification: 47H06; 47J05; 47J25; 47H10; 47H17.

Keywords: $\lambda$-strict pseudocontraction, 2-uniformly smooth Banach space, modified Mann iteration, strong convergence

\section{Introduction}

Let $T$ be a pseudocontractive mapping defined on a real smooth Banach space $E$. We consider the problem of finding a solution $z \in E$ of the fixed point equation $x=T x$. One classical way to study pseudocontractive mappings is to use a strong pseudocontraction to approximate a pseudocontractive mapping $T$. More precisely take $t \in(0,1)$ and $u \in E$ define a strong pseudocontraction $T_{t}$ by $T_{t} x=t u+(1-\mathrm{t}) T x$. In [1, Corollary 2],Deimling proves that $T_{t}$ has a unique fixed point $x_{t}$, i.e.,

$$
x_{t}=t u+(1-t) T x_{t} .
$$

This implicit iteration was introduced by Browder [2] for a nonexpansive mapping $T$ in Hilbert space. Halpern [3] was the first who introduced the following explicit iteration scheme for a nonexpansive mapping $T$ which was referred to as Halpern iteration: for $u, x_{0} \in K, \alpha_{n} \in[0,1]$,

$$
x_{n+1}=\alpha_{n} u+\left(1-\alpha_{n}\right) T x_{n} .
$$

Convergence of this two schemes have been studied by many researchers with various types of additional conditions. For the studies of a nonexpansive mapping $T$, see Bruck [4,5], Reich [6,7], Song-Xu [8], Takahashi-Ueda [9], Suzuki [10], and many others. For the studies of a continuous pseudocontractive mapping $T$, see MoralesJung [11], Schu [12], Chidume-Zegeye [13], Chidume-Udomene [14], Udomene [15], Chidume-Ofoedu [16], Chen-Song-Zhou [17,18], Song [19-21], Song-Chen [22,23] and others. The following results play a key role in proving strong convergence of Halpern iteration. 
Theorem 1.1 [11,22,23] Let E be a reflexive Banach space which has both the fixed point property for nonexpansive self-mappings and a uniformly Gâteaux differ-entiable norm or be a reflexive and strictly convex Banach space with a uniformly Gâteaux differentiable norm. Assume that $K$ is a nonempty, closed and convex subset of E. Suppose that $T$ is a continuous pseudocontractive mapping from $K$ into $E$ with $F(T) \neq \emptyset$. Then, as $t \rightarrow 0, x_{b}$ defined by (1.1) converges strongly to a fixed point of $T$.

Theorem 1.2. [22] Let $K$ be nonempty, closed and convex subset of a Banach space $E$ with a uniformly Gâteaux differentiable norm and let $T: K \rightarrow K$ be a continuous pseudocontractive mapping with a fixed point. Assume that there exists a bounded sequence $\left\{x_{n}\right\}$ such that $\lim _{n \rightarrow \infty}\left\|x_{n}-T x_{n}\right\|=0$ and $p=\lim _{t \rightarrow 0} z_{t}$ exists, where $\left\{z_{t}\right\}$ is defined by (1.1). Then,

$$
\limsup _{n \rightarrow \infty}\left\langle u-p, J\left(x_{n}-p\right)\right\rangle \leq 0 .
$$

Mann [24] introduced the following iteration for $T$ in a Hilbert space:

$$
x_{n+1}=\alpha_{n} x_{n}+\left(1-\alpha_{n}\right) T x_{n}
$$

where $\left\{\alpha_{n}\right\}$ is a sequence in [0,1]. Latterly, Reich [25] studied this iteration in a uniformly convex Banach space with a Fréchet differentiable norm, and obtained that if $T$ has a fixed point and $\sum_{n=0}^{\infty} \alpha_{n}\left(1-\alpha_{n}\right)=\infty$, then the sequence $\left\{x_{n}\right\}$ converges weakly to a fixed point of $T$. This Mann's iteration process has extensively been studied over the last 20 years for constructions of fixed points of nonlinear mappings and for solving nonlinear operator equations involving monotone, accretive and pseudocontractive operators (see, e.g., [16,26-34] and others). In an infinite-dimensional Hilbert space, the classical Mann's iteration algorithm (1.3) has, in general, only weak convergence, even for nonexpansive mappings. In order to get strong convergence result, one has to modify the Mann's iteration algorithm. Several attempts have been made and many important results have been reported (see, e.g., [12-16,35-37] and others). Recently, Zhou [37] obtained strong convergence theorem for the following iterative sequence in a 2-uniformly smooth Banach space: for $u, x_{0} \in E$ and $\lambda$-strict pseudocontraction $T$,

$$
x_{n+1}=\beta_{n} u+\gamma_{n} x_{n}+\left(1-\beta_{n}-\gamma_{n}\right)\left[\alpha_{n} T x_{n}+\left(1-\alpha_{n}\right) x_{n}\right],
$$

where $\left\{\alpha_{n}\right\},\left\{\beta_{n}\right\}$ and $\left\{\gamma_{n}\right\}$ in $(0,1)$ satisfy:

(i) $a \leq \alpha_{n} \leq \frac{\lambda}{K^{2}}$ for some $a>0$ and for all $n \geq 0$;

(ii) $\lim _{n \rightarrow \infty} \beta_{n}=0$ and $\sum_{n=1}^{\infty} \beta_{n}=\infty$;

(iii) $\lim _{n \rightarrow \infty}\left|\alpha_{n+1}-\alpha_{n}\right|=0$;

(iv) $0<\liminf _{n \rightarrow \infty} \gamma_{n} \leq \limsup _{n \rightarrow \infty} \gamma_{n}<1$.

Very recently, Zhang and Su [38] extended Zhou's results to q-uniformly smooth Banach space. However, the above results excluded $\gamma_{n} \equiv 0$ and $\gamma_{n} \equiv \frac{1}{n+1}$.

In this article, we deal with iterative schemes generated by the following iterative sequence (in (1.4), $\gamma_{n} \equiv 0$ ) for $\lambda$-strict pseudocontraction $T$ : 


$$
x_{n+1}=\beta_{n} u+\left(1-\beta_{n}\right)\left[\alpha_{n} T x_{n}+\left(1-\alpha_{n}\right) x_{n}\right],
$$

and obtain its strong convergence whenever $\left\{\alpha_{n}\right\}$ and $\left\{\beta_{n}\right\}$ satisfy the following conditions:

(i) $\alpha_{n} \in\left[a, \frac{\lambda}{K^{2}}\right]$ such that $\sum_{n=1}^{\infty}\left|\alpha_{n+1}-\alpha_{n}\right|<\infty$;

(ii) $\lim _{n \rightarrow \infty} \beta_{n}=0, \sum_{n=1}^{\infty} \beta_{n}=\infty$ and $\sum_{n=1}^{\infty}\left|\beta_{n+1}-\beta_{n}\right|<\infty$.

Our result not only complements and develops corresponding ones of Zhou [37, Theorem 2.3] (see also Zhang and Su [38, Theorem 4.1], where $\gamma_{n} \equiv 0$ ), but also extend main result of Chidume-Chidume [35] and $\mathrm{Kim}-\mathrm{Xu}$ [36] from nonexpansive mappings to $\lambda$-strict pseudocontractions.

\section{Preliminaries}

Throughout this article, a Banach space $E$ will always be over the real scalar field. We denote its norm by $\|\cdot\|$ and its dual space by $E^{*}$. The value of $x^{*} \in E^{*}$ at $y \in E$ is denoted by $\langle y, x\rangle$ and the normalized duality mapping from $E$ into $2^{E_{*}}$ is denoted by $J$, that is, $J(x)=\left\{f \in E^{*}:\langle x, f\rangle=\|x\|\|f\|,\|x\|=\|f\|\right.$. Let $F(T)=\{x \in E: T x=x\}$ be the set of all fixed point of a mapping $T$.

Recall that a mapping $T$ with domain $D(T)$ and range $R(T)$ in Banach space $E$ is called strongly pseudo-contractive if, for all $x, y \in D(T)$, there exist $k \in(0,1)$ and $j(x-$ $y) \in J(x-y)$ such that

$$
\langle T x-T y, j(x-y)\rangle \leq k|| x-\left.y\right|^{2}
$$

or, equivalently,

$$
\langle(x-T x)-(y-T y), j(x-y)\rangle \geq(1-k)\|x-y\|^{2}
$$

while $T$ is said to be pseudo-contractive if (2.1) or (2.2) holds for $k=1$. A mapping $T$ is said to be Lipschitzian if, for all $x, y \in K$, there exists $L>0$ such that

$$
\|T x-T y\| \leq L\|x-y\| .
$$

A mapping $T$ is called non-expansive if $L=1$ and, further, $T$ is said to be contractive if $L<1$. An important class of mappings closely related to the class of pseudo-contractive mappings is that of accretive mappings. A mapping $A$ is accretive if and only if ( $I$ $A$ ) is pseudo-contractive. The accretive mappings were independently introduced by Browder [39] and Kato [40] in 1967. The importance of these mappings is well known. A mapping $T$ is called $\lambda$-strictly pseudocontractive, if for all $x, y \in D(T)$, there exists $\lambda$ $\in(0,1)$ and $j(x-y) \in J(x-y)$ such that

$$
\langle T x-T y, j(x-y)\rangle \leq\|x-y\|^{2}-\lambda\|x-y-(T x-T y)\|^{2} .
$$

It is obvious that $\lambda$-strictly pseudocontractive mapping is Lipschitzian with $L=\frac{\lambda+1}{\lambda}$. The class of nonexpansive mappings is a subclass of strictly pseudocontractive mappings in Hilbert space, but the converse implication may be false. We remark that the class of strongly pseudo-contractive mappings is independent from the class of $\lambda$-strict pseudo-contractions. This can be seen from the existing examples (see, e.g., [30,37]). 
Let $S(E):=\{x \in E ;\|x\|=1\}$ denote the unit sphere of a Banach space $E$. The space $E$ is said to have (i) a Gâteaux differentiable norm (we also say that $E$ is smooth), if the limit

$$
\lim _{t \rightarrow 0} \frac{\|x+t y\|-\|x\|}{t}
$$

exists for each $x, y \in S(E)$; (ii) a uniformly Gâteaux differentiable norm, if for any $y$ in $S(E)$, the limit (2.4) is uniformly attained for $x \in S(E)$; (iii) a Fréchet differentiable norm, if for any $x \in S(E)$, the limit (2.4) is attained uniformly for $y \in S(E)$; (iv) a uniformly Fréchet differentiable norm (we also say that $E$ is uniformly smooth), if the limit (2.4) is attained uniformly for all $(x, y) \in S(E) \times S(E)$; (v) fixed point property for nonexpansive self-mappings, if each non-expansive self-mapping defined on any bounded, closed convex subset $K$ of $E$ has at least one fixed point. Let $\rho_{E}:[0, \infty) \rightarrow[0, \infty)$ be the modulus of smoothness of $E$ defined by

$$
\rho_{E}(t)=\sup \left\{\frac{1}{2}(\|x+y\|+\|x-y\|)-1: x \in S(E),\|y\| \leq t\right\} .
$$

Let $q>1$. A Banach space $E$ is said to be $q$-uniformly smooth, if there exists a fixed constant $c>0$ such that $\rho_{E}(t)<c t^{q}$. It is well known that $E$ is uniformly smooth if and only if $\lim _{t \rightarrow 0} \frac{\rho_{E}(t)}{t}=0$. If $E$ is $q$-uniformly smooth, then $E$ is uniformly smooth, and hence the norm of $E$ is uniformly Fréchet differentiable, in particular, the norm of $E$ is Fréchet differentiable. Typical example of uniformly smooth Banach spaces is $L_{p}(p>1)$. More precisely, $L_{p}$ is $\min \{p, 2\}$-uniformly smooth for every $p>1$.

Lemma 2.1.(Zhou [37]) Let $E$ be a real 2-uniformly smooth Banach space with the best smooth constant $K, C$ be a nonempty subset of $E$, and let $T: C \rightarrow C$ be a $\lambda$-strict pseudocontraction. For any $\alpha \in(0,1)$, we define $T_{\alpha}=(1-\alpha) x+\alpha T x$. Then, as $\alpha \in\left(0, \frac{\lambda}{K^{2}}\right], T_{\alpha}: C \rightarrow$ Cis nonexpansive such that $F\left(T_{\alpha}\right)=F(T)$.

Lemma 2.2. (Liu [34] and $\mathrm{Xu}[41])$ Let $\left\{a_{n}\right\}$ be a sequence of nonnegative real numbers satisfying the property:

$$
a_{n+1} \leq\left(1-t_{n}\right) a_{n}+b_{n}+t_{n} c_{n}
$$

where $\left\{t_{n}\right\},\left\{b_{n}\right\}$ and $\left\{c_{n}\right\}$ satisfy the restrictions:

(i) $\sum_{n=0}^{\infty} t_{n}=\infty$; (ii) $\sum_{n=0}^{\infty} b_{n}<+\infty$; (iii) $\limsup _{n \rightarrow \infty} c_{n} \leq 0$.

Then, $\left\{a_{n}\right\}$ converges to zero as $n \rightarrow \infty$.

\section{Main result}

Theorem 3.1 Let E be a real 2-uniformly smooth Banach space with the best smooth constant $K$ and let $C$ be a nonempty, closed and convex subset of $E$. Suppose that $T: C \rightarrow C$ is a $\lambda$-strict pseudocontraction with $F(T) \neq \emptyset$. Given $u, x_{0} \in C$, a sequence $\left\{x_{n}\right\}$ is generated by

$$
\left\{\begin{array}{l}
y_{n}=\alpha_{n} T x_{n}+\left(1-\alpha_{n}\right) x_{n} \\
x_{n+1}=\beta_{n} u+\left(1-\beta_{n}\right) y_{n}
\end{array}\right.
$$

where $\left\{\beta_{n}\right\}$ and $\left\{\alpha_{n}\right\}$ in $(0,1)$ satisfy the following control conditions:

(i) $\alpha_{n} \in\left[a, \frac{\lambda}{K^{2}}\right]$ for some constant $a \in\left(0, \frac{\lambda}{K^{2}}\right)$ such that $\sum_{n=1}^{\infty}\left|\alpha_{n+1}-\alpha_{n}\right|<\infty$; 
(ii) $\lim _{n \rightarrow \infty} \beta_{n}=0, \sum_{n=1}^{\infty} \beta_{n}=\infty$ and $\sum_{n=1}^{\infty}\left|\beta_{n+1}-\beta_{n}\right|<\infty$.

Then, $\left\{x_{n}\right\}$ converges strongly to a fixed point of $T$.

Proof. The proof will be divided into four steps.

Step 1. The sequence $\left\{x_{n}\right\}$ is bounded. Let $T_{\alpha_{n}}=\alpha_{n} T+\left(1-\alpha_{n}\right) I$. Then, $T_{\alpha_{n}}$ is nonexpansive for every $n$ by Lemma 2.1 and so, for $p \in F(T)$, we have

$$
\begin{aligned}
\left\|x_{n+1}-p\right\| & =\left\|\beta_{n}(u-p)+\left(1-\beta_{n}\right)\left(T_{\alpha_{n}} x_{n}-p\right)\right\| \\
& \leq \beta_{n}\|u-p\|+\left(1-\beta_{n}\right)\left\|T_{\alpha_{n}} x_{n}-p\right\| \\
& \leq \beta_{n}\|u-p\|+\left(1-\beta_{n}\right)\left\|x_{n}-p\right\| \\
& \leq \max \left\{\left\|x_{n}-p\right\|,\|u-p\|\right\} \\
& \vdots \\
& \leq \max \left\{\left\|x_{0}-p\right\|,\|u-p\|\right\} .
\end{aligned}
$$

Consequently, both $\left\{x_{n}\right\}$ and $\left\{y_{n}\right\}$ are bounded. This implies the boundedness of $\left\{T x_{n}\right\}$ from the inequality $\left\|T x_{n}-p\right\| \leq \frac{1+\lambda}{\lambda}\left\|x_{n}-p\right\|$.

Let $M>0$ be a constant such that $M \geq \sup _{n \in \mathbb{N}}\left\{\|u\|,\left\|x_{n}\right\|,\left\|T x_{n}\right\|\right\}$.

Step 2. Since $y_{n}=T_{\alpha_{n}} x_{n}=\alpha_{n} T x_{n}+\left(1-\alpha_{n}\right) x_{n}$, then

$$
\left\|y_{n}\right\|=\left\|\alpha_{n} T x_{n}+\left(1-\alpha_{n}\right) x_{n}\right\| \leq \alpha_{n}\left\|T x_{n}\right\|+\left(1-\alpha_{n}\right)|| x_{n} \| \leq M .
$$

Furthermore, we have

$$
\begin{aligned}
\left\|y_{n+1}-y_{n}\right\| & =\left\|T_{\alpha_{n+1}} x_{n+1}-T_{\alpha_{n}} x_{n}\right\| \\
& \leq\left\|T_{\alpha_{n+1}} x_{n+1}-T_{\alpha_{n+1}} x_{n}\right\|+\left\|T_{\alpha_{n+1}} x_{n}-T_{\alpha_{n}} x_{n}\right\| \\
& \leq\left\|x_{n+1}-x_{n}\right\|+\left\|\alpha_{n+1} T x_{n}+\left(1-\alpha_{n+1}\right) x_{n}-\alpha_{n} T x_{n}-\left(1-\alpha_{n}\right) x_{n}\right\| \\
& \leq\left\|x_{n+1}-x_{n}\right\|+\left|\alpha_{n+1}-\alpha_{n}\left\||| x_{n}-T x_{n}\right\|\right. \\
& \leq\left\|x_{n+1}-x_{n}\right\|+2 M\left|\alpha_{n+1}-\alpha_{n}\right| .
\end{aligned}
$$

From (3.1), it follows

$$
\begin{aligned}
\left\|x_{n+2}-x_{n+1}\right\| & =\left\|\beta_{n+1} u+\left(1-\beta_{n+1}\right) y_{n+1}-\beta_{n} u-\left(1-\beta_{n}\right) y_{n}\right\| \\
& \leq\left|\beta_{n+1}-\beta_{n}\right|\left(|| u \|+|| y_{n+1}||\right)+\left(1-\beta_{n}\right)|| y_{n+1}-y_{n} \| \\
& \leq 2 M\left|\beta_{n+1}-\beta_{n}\right|+\left(1-\beta_{n}\right)|| y_{n+1}-y_{n} \| .
\end{aligned}
$$

Substituting (3.2) into (3.3) yields

$$
|| x_{n+2}-x_{n+1}|| \leq\left(1-\beta_{n}\right)|| x_{n+1}-x_{n}||+2 M\left|\alpha_{n+1}-\alpha_{n}\right|+2 M\left|\beta_{n+1}-\beta_{n}\right| .
$$

From the assumptions on $\left\{\alpha_{n}\right\}$ and $\left\{\beta_{n}\right\}$ and using Lemma 2.3, we conclude that

$$
\lim _{n \rightarrow \infty}|| x_{n+1}-x_{n} \|=0 .
$$

From the definition of $x_{n}$ and since $\lim _{n \rightarrow \infty} \beta_{n}=0$, it follows

$$
\lim _{n \rightarrow \infty}\left\|x_{n+1}-y_{n}\right\|=\lim _{n \rightarrow \infty} \beta_{n}\left\|u-T x_{n}\right\|=0 .
$$

Combining (3.4), we have

$$
\lim _{n \rightarrow \infty}\left\|x_{n}-y_{n}\right\|=0 .
$$


Thus, we obtain

$$
\lim _{n \rightarrow \infty}\left\|x_{n}-T x_{n}\right\|=\lim _{n \rightarrow \infty} \frac{\left\|x_{n}-y_{n}\right\|}{\alpha_{n}}=0 .
$$

Step 3. There exists $z \in F(T)$ such that

$$
\limsup _{n \rightarrow \infty}\left\langle u-z, J\left(x_{n+1}-z\right)\right\rangle \leq 0
$$

Since $E$ is 2-uniformly smooth, then $E$ is a reflexive Banach space which has both the fixed point property for non-expansive self-mappings and a uniformly Gâteaux differentiable norm. Then, from Theorem 1.1, as $t \rightarrow 0, x_{t}$, defined by (1.1) converges strongly to a fixed point $z$ of $T$. The desired conclusion follows from Theorem 1.2.

Step 4. $\lim _{n \rightarrow \infty} x_{n}=z$. In fact,

$$
\begin{aligned}
\left\|x_{n+1}-z\right\|^{2} & =\left\langle\beta_{n}(u-z)+\left(1-\beta_{n}\right)\left(y_{n}-z\right), J\left(x_{n+1}-z\right)\right\rangle \\
& \leq \beta_{n}\left\langle u-z, J\left(x_{n+1}-z\right)\right\rangle+\left(1-\beta_{n}\right)\left\|T_{\alpha_{n}} x_{n}-z \mid\right\| J\left(x_{n+1}-z\right) \| \\
& \leq \beta_{n}\left\langle u-z_{\prime} J\left(x_{n+1}-z\right)\right\rangle+\left(1-\beta_{n}\right) \frac{\left\|x_{n}-z\right\|^{2}+\left\|x_{n+1}-z\right\|^{2}}{2} \\
& \leq\left(1-\beta_{n}\right) \frac{\left\|x_{n}-z\right\|^{2}}{2}+\frac{\left\|x_{n+1}-z\right\|^{2}}{2}+\beta_{n}\left\langle u-z_{\prime} J\left(x_{n+1}-z\right)\right\rangle,
\end{aligned}
$$

which implies that

$$
\left\|x_{n+1}-z\right\|^{2} \leq\left(1-\beta_{n}\right)\left\|x_{n}-z\right\|^{2}+2 \beta_{n}\left\langle u-z, J\left(x_{n+1}-z\right)\right\rangle,
$$

and hence $\lim _{n \rightarrow \infty}\left\|x_{n}-z\right\|=0$ because of Lemma 2.2. This completes the proof.

Remark 1. Theorem 3.1 is applicable to $l_{p}$ and $L_{p}$ for all $p \geq 2$, however, we do not know whether it works for $L_{p}$ for $1<p<2$.

Remark 2. In Theorem 3.1, if the condition $\sum_{n=1}^{\infty}\left|\beta_{n+1}-\beta_{n}\right|<\infty$ is replaced by $\lim _{n \rightarrow \infty} \frac{\beta_{n+1}}{\beta_{n}}=1$, the conclusion still holds.

Remark 3. Theorem 3.1 not only complements and develops corresponding result of Zhou [37, Theorem 3.2] (see also Zhang and $\mathrm{Su}$ [38, Theorem 4.1] where $\gamma_{n} \equiv 0$ ), but also extend main result of Chidume-Chidume [35] and Kim-Xu [36] from nonexpansive mappings to $\lambda$-strict pseudocontractions.

Corollary 3.2 Let E be a reflexive Banach space which has both the fixed point property for non-expansive self-mappings and a uniformly Gâteaux differentiable norm and let $C$ be a nonempty, closed and convex subset of $E$. Suppose that $T: C \rightarrow C$ is a nonexpansive mapping with $F(T) \neq \emptyset$. Given $u, x_{0} \in C$, a sequence $\left\{x_{n}\right\}$ is generated by (3.1), where $\left\{\alpha_{n}\right\}$ and $\left\{\beta_{n}\right\}$ in $(0,1)$ satisfy the following control conditions:

(i) $\alpha_{n} \in(0,1)$ such that $\sum_{n=1}^{\infty}\left|\alpha_{n+1}-\alpha_{n}\right|<\infty$;

(ii) $\lim _{n \rightarrow \infty} \beta_{n}=0, \sum_{n=1}^{\infty} \beta_{n}=\infty$;

(iii) either $\sum_{n=1}^{\infty}\left|\beta_{n+1}-\beta_{n}\right|<\infty$ or $\lim _{n \rightarrow \infty} \frac{\beta_{n+1}}{\beta_{n}}=1$.

Then, $\left\{x_{n}\right\}$ converges strongly to a fixed point of $T$. 
Proof. Let $T_{\alpha_{n}}=\alpha_{n} T+\left(1-\alpha_{n}\right) I$. Clearly, $T_{\alpha_{n}}$ is nonexpansive and $F(T)=F\left(T_{\alpha_{n}}\right)$ for each $n$. Therefore, following the same proof technique of Theorem 3.1, the desired result is obtained.

Remark 4. Theorem 3.1 of Chidume-Chidume [35] and Theorem 1 of Kim-Xu [36] can be regarded as a special case of Corollary 3.2, respectively. In fact, if $\alpha_{n} \equiv \delta \in(0$, 1) in Corollary 3.2, then Theorem 3.1 of Chidume-Chidume [35] is reached; if in Corollary 3.2, $E$ is a uniformly smooth Banach space and the conditions $\lim _{n \rightarrow \infty} a_{n}=1$ and $\sum_{n=1}^{\infty}\left(1-\alpha_{n}\right)=\infty$ are added, then Theorem 1 of Kim-Xu [36] is obtained.

\section{Acknowledgements}

The authors were thank the editor and the anonymous referee for useful comments and valuable suggestions on the language and structure of our manuscript.

\section{Authors' contributions}

YS carried out the iteration studies, participated in the sequence alignment, and drafted the manuscript. XC participated in the design of the study and performed the algorithmic analysis and revised the manuscript. All authors read and approved the final manuscript.

\section{Competing interests}

The authors declare that they have no competing interests.

Received: 14 July 2011 Accepted: 6 December 2011 Published: 6 December 2011

\section{References}

1. Deimling, K: Zero of accretive operators. Manuscripta Math. 13, 365-374 (1974)

2. Browder, FE: Fixed-point theorems for noncompact mappings in Hilbert space. Proc Natl Acad Sci USA. 53, 1272-1276 (1965)

3. Halpern, B: Fixed points of nonexpansive maps. Bull Amer Math Soc. 73, 957-961 (1967)

4. Bruck, RE: A simple proof of the mean ergodic theorem for nonlinear contractions in Banach spaces. Israel J Math. 32, 107-116 (1979)

5. Bruck, RE: On the convex approximation property and the asymptotic behavior of nonlinear contractions in Banach spaces. Israel J Math. 38, 304-314 (1981)

6. Reich, S: Approximating zeros of accretive operators. Proc Amer Math Soc. 51, 381-384 (1975)

7. Reich, S: Strong convergence theorems for resolvents of accretive operators in Banach spaces. J Math Anal Appl. 75, 287-292 (1980)

8. Song, Y, Xu, S: Strong convergence theorems for nonexpansive semigroup in Banach spaces. J Math Anal Appl. 338, 152-161 (2008)

9. Takahashi, W, Ueda, Y: On Reich's strong convergence for resolvents of accretive operators. J Math Anal Appl. 104, 546-553 (1984)

10. Suzuki, T: Strong convergence theorems for infinite families of nonexpansive mappings in general Banach spaces. Fixed Point Theory Appl. 2005(1), 103-123 (2005)

11. Morales, CH, Jung, JS: Convergence of paths for pseudo-contractive mappings in Banach spaces. Proc Amer Math Soc. 128, 3411-3419 (2000)

12. Schu, J: Approximating fixed points of Lipschitzian pseudocontractive mappings. Houston J Math. 19, 107-115 (1993)

13. Chidume, CE, Zegeye, H: Approximate fixed point sequences and convergence theorems for Lipschitz pseudocontractive maps. Proc Amer Math Soc. 132, 831-840 (2004)

14. Chidume, CE, Udomene, A: Strong convergence theorems for uniformly continuous pseudo-contractive maps. J Math Anal Appl. 323, 88-99 (2006)

15. Udomene, A: Path convergence, approximation of fixed points and variational solutions of Lipschitz pseudocontractions in Banach spaces. Nonlinear Anal. 67, 2403-2414 (2007)

16. Chidume, CE, Ofoedu, EU: A new iteration process for generalized Lipschitz pseudo-contractive and generalized Lipschitz accretive mappings. Nonlinear Anal. 67, 307-315 (2007)

17. Chen, R, Song, Y, Zhou, H: Viscosity approximation methods for continuous pseudocontrac-tive mappings. Acta Math Sin Chin Ser. 49, 1275-1278 (2006)

18. Chen, R, Song, Y, Zhou, H: Convergence theorems for implicit iteration process for a finite family of continuous pseudocontractive mappings. J Math Anal Appl. 314, 701-709 (2006)

19. Song, Y: A note on the paper "A new iteration process for generalized Lipschitz pseudo-contractive and generalized Lipschitz accretive mappings". Nonlinear Anal. 68, 3047-3049 (2008)

20. Song, Y: On a Mann type implicit iteration process for continuous pseudo-contractive mappings. Nonlinear Anal. 67, 3058-3063 (2007)

21. Song, Y: Strong convergence of viscosity approximation methods with strong pseudocontrac-tion for Lipschitz pseudocontractive mappings. Positivity. 13, 643-655 (2009)

22. Song, Y, Chen, R: Convergence theorems of iterative algorithms for continuous pseudocon-tractive mappings. Nonlinear Anal. 67, 486-497 (2007)

23. Song, Y, Chen, R: An approximation method for continuous pseudocontractive mappings. J Inequal Appl2006, 1-9. Article ID 28950, 
24. Mann, WR: Mean value methods in iteration. Proc Amer Math Soc. 4, 506-510 (1953)

25. Reich, S: Weak convergence theorems for nonexpansive mappings in Banach spaces. J Math Anal Appl. 67, 274-276 (1979)

26. Chidume, CE, Moore, C: Fixed point iteration for pseudo-contractive maps. Proc Amer Math Soc. 127(4), 1163-1170 (1999)

27. Chidume, CE: Iterative approximation of Lipschitz strictly pseudo-contractive mappings. Proc Amer Math Soc. 99(2), 283-288 (1987)

28. Chidume, CE: Approximation of fixed points of strongly pseudo-contractive mappings. Proc Amer Math Soc. 120(2), 545-551 (1994)

29. Chidume, CE: Global iteration schemes for strongly pseudo-contractive maps. Proc Amer Math Soc. 126(9), 2641-2649 (1998)

30. Chidume, CE, Mutangadura, SA: An example on the Mann iteration method for Lipschitz pseudocontractions. Proc Amer Math Soc. 129(8), 2359-2363 (2001)

31. Deng, L: On Chidume's open problems. J Math Anal Appl. 174(2), 441-449 (1993)

32. Deng, L, Ding, XP: Iterative approximation of Lipschitz strictly pseudo-contractive mappings in uniformly smooth Banach spaces. Nonlinear Anal. 24(7), 981-987 (1995)

33. Hicks, TL, Kubicek, JR: On the Mann iteration process in Hilbert space. J Math Anal Appl. 59, 498-504 (1977)

34. Liu, LS: Ishikawa and Mann iteration process with errors for nonlinear strongly accretive mappings in Banach spaces. J Math Anal Appl. 194, 114-125 (1995)

35. Chidume, CE, Chidume, CO: Iterative approximation of fixed points of nonexpansive mappings. J Math Anal Appl. 318, 288-295 (2006)

36. Kim, TH, Xu, HK: Strong convergence of modified Mann iterations. Nonlinear Anal. 61, 51-60 (2005)

37. Zhou, $\mathrm{H}$ : Convergence theorems for $\lambda$-strict pseudo-contractions in 2-uniformly smooth Banach spaces. Nonlinear Anal. 69(9), 3160-3173 (2008)

38. Zhang, $\mathrm{H}, \mathrm{Su}, \mathrm{Y}$ : Convergence theorems for strict pseudo-contractions in q-uniformly smooth Banach spaces. Nonlinear Anal. 71, 4572-4580 (2009)

39. Browder, FE: Nonlinear equations of evolution and nonlinear accretive operators in Banach spaces. Bull Amer Math Soc 73, 470-475 (1967). Part 2 (1976)

40. Kato, T: Nonlinear semigroups and evolution equations. J Math Soc Japan. 19, 508-520 (1967)

41. Xu, HK: Iterative algorithms for nonlinear operators. J London Math Soc. 66, 240-256 (2002)

doi:10.1186/1687-1812-2011-95

Cite this article as: Chai and Song: Convergence theorem for an iterative algorithm of $\lambda$-strict pseudocontraction. Fixed Point Theory and Applications 2011 2011:95.

\section{Submit your manuscript to a SpringerOpen ${ }^{\odot}$} journal and benefit from:

- Convenient online submission

- Rigorous peer review

- Immediate publication on acceptance

- Open access: articles freely available online

- High visibility within the field

- Retaining the copyright to your article

Submit your next manuscript at $\boldsymbol{s p r i n g e r o p e n . c o m ~}$ 